\title{
Catalyst-Support Interactions during Carbon Nanotube Synthesis
}

\author{
M. Tanase, ${ }^{* / *}$, S. Mazzucco, ${ }^{* * *}$ and R. Sharma**
}

* Institute for Research in Electronics and Applied Physics, University of Maryland, College Park, MD 20742-3511

** Center for Nanoscale Science and Technology, National Institute of Science and Technology, Gaithersburg, MD 20899-6203

It has been shown that the catalyst-support interactions play an important role in metal-catalyzed carbon nanofiber growth, which could be due to physical or chemical interaction. [1] However, the exact nature of the catalyst-support interaction, especially for carbon nanotube (CNT) growth is still unclear. Here we report the dynamic observation of the structural changes occurring due to chemical interaction between the $\mathrm{Fe}$ catalyst and the $\mathrm{SiO}_{2}$ support during CNT growth.

The formation of CNT using Fe-containing catalysts is studied in situ in an environmental scanning transmission electron microscope (ESTEM) by depositing the catalyst nanoparticles and growing the CNT in successive steps. $20 \mathrm{~Pa}$ of Nonacarbonyldiiron $\left(\mathrm{Fe}_{2}(\mathrm{CO})_{9}\right)$ vapors were introduced in the sample area of the ESTEM and nanoparticles between $15 \mathrm{~nm}$ to $20 \mathrm{~nm}$ in diameter were fabricated by electron-beam induced decomposition of the iron precursor on a perforated $\mathrm{SiO}_{2}$ thin film at 150 ${ }^{\circ} \mathrm{C}$ using a focused electron beam. After the column was evacuated from the iron precursor, samples were heated to $680^{\circ} \mathrm{C}$ in $\approx 12 \mathrm{~Pa}$ of $\mathrm{H}_{2}$ in order to remove the co-deposited carbon and to prevent the oxidation of the iron-containing catalyst. Hydrogen was then replaced by $\approx 2 \mathrm{~Pa}$ of flowing acetylene $\left(\mathrm{C}_{2} \mathrm{H}_{2}\right)$ at the same temperature. The formation of the catalyst nanoparticles and the growth of CNT were recorded using high resolution digital videos. The crystallographic structures were periodically sampled using fast Fourier transform (FFT's) of frames extracted from the high resolution video.

We observed that the deposited $\mathrm{Fe}$ undergoes a series of reactions with the $\mathrm{SiO}_{2}$ substrate to form the intermediate phases $\left(\mathrm{Fe}_{2} \mathrm{SiO}_{4}\right)_{0.546}\left(\mathrm{Fe}_{3} \mathrm{O}_{4}\right)_{0.454}$ and $\mathrm{Fe}_{2} \mathrm{SiO}_{4}$. In situ monitoring reveals that these structures decompose and react with acetylene to form $\mathrm{Fe}_{3} \mathrm{C}$, the active structure towards the formation of CNT's. [2, 3] A particle of $\left(\mathrm{Fe}_{2} \mathrm{SiO}_{4}\right)_{0.546}\left(\mathrm{Fe}_{3} \mathrm{O}_{4}\right)_{0.454}$ with a high degree of crystallinity is shown in Fig. 1. After about 7 seconds, a structural transformation is initiated, indicated by the temporary loss of fringe contrast. The structure changes gradually to $\mathrm{Fe}_{3} \mathrm{C}$ before the particle starts forming a CNT (Fig. 2). The CNT formation reaction slows down markedly when the grown CNT completely encases the catalytic nanoparticle and the rate of supply of carbon from the acetylene gas becomes diffusion limited. At the end of the CNT formation the original complex silicide $\left(\mathrm{Fe}_{2} \mathrm{SiO}_{4}\right)_{0.546}\left(\mathrm{Fe}_{3} \mathrm{O}_{4}\right)_{0.454}$ structure has completely transformed and the structure of the active nanoparticle remains compatible with $\mathrm{Fe}_{3} \mathrm{C}$ (Fig. 3) though the overlying CNT structure on the particle prevents a conclusive determination of its structure (Fig. 4).

\section{References}

[1] Vander Wal et al., Carbon 29 (2001) 2277

[2] H. Yoshida et al., Nano Lett., 8 (7) (2008) 2082

[3] R. Sharma et al., Nano Lett. 9 (2) (2009) 689.

[4] The use of facilities in the LeRoy Eyring Center for Solid State Science at Arizona State University is gratefully acknowledged. 


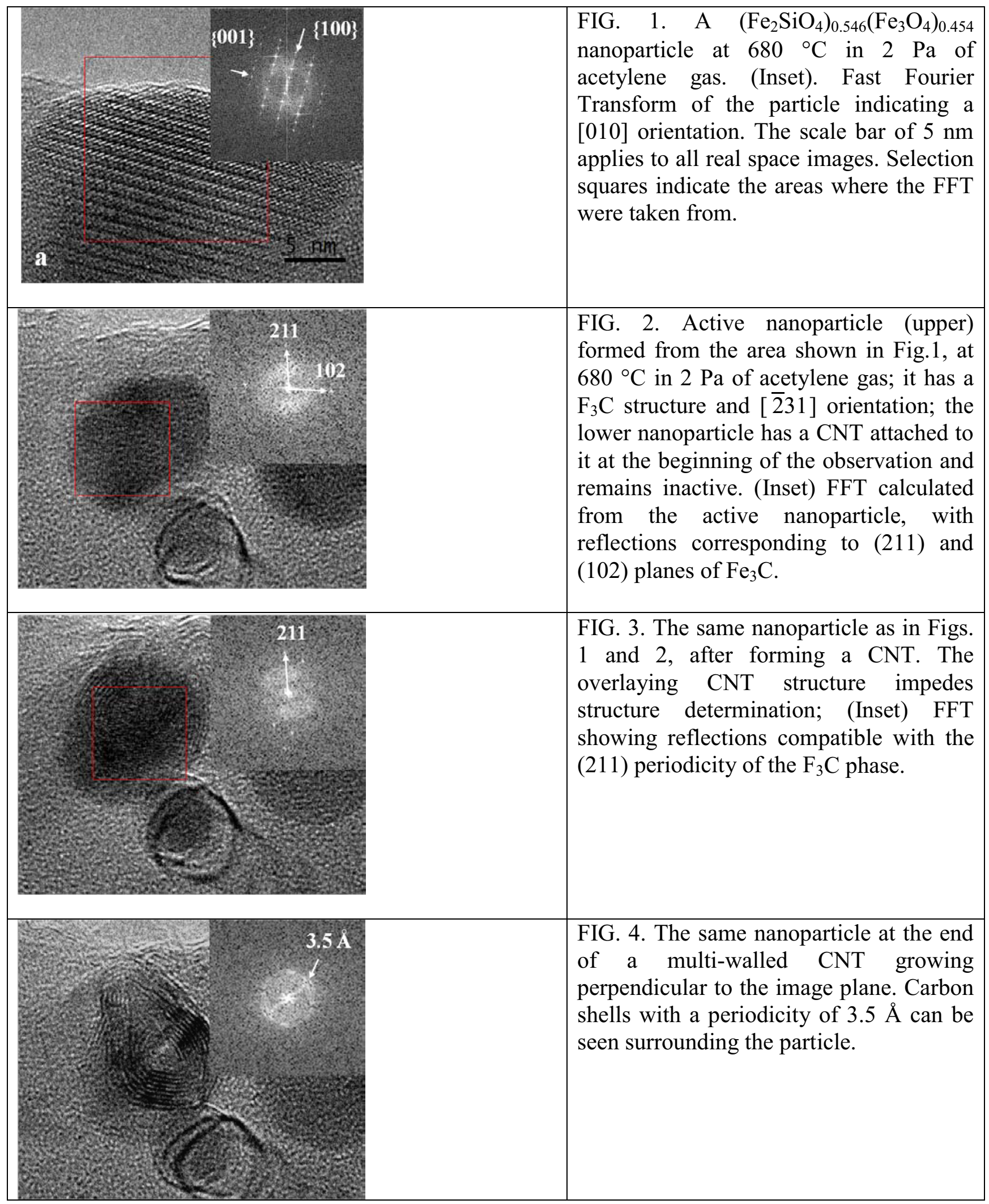

